\title{
Qualidade de resistência de peles de Tilápia do Nilo submetidas ao curtimento com
}

\section{tanino vegetal}

\author{
Resistance quality of Nile Tilapia hides subjected to tanning with vegetable tannin \\ Calidad de resistencia de las pieles de tilapia del Nilo sometidas a curtido con tanino vegetal
}

Fabricio Vieira dos Santos

ORCID: https://orcid.org/0000-0002-1242-8181 Universidade Estadual de Maringá, Brasil

E-mail: fabriciovieiradsantos@gmail.com

Gustavo Lazarini Martins

ORCID: https://orcid.org/0000-0003-2771-3492 Universidade Estadual de Maringá, Brasil

E-mail: gustavolazarinim@gmail.com

Gislaine Gonçalves Oliveira

ORCID: https://orcid.org/0000-0002-7819-3493

Universidade Estadual de Maringá, Brasil

E-mail: gislaine_oliveria14@hotmail.com

Sabrina Campos Sbaraini

ORCID: https://orcid.org/0000-0002-7165-6563 Universidade Estadual de Maringá, Brasil

E-mail: sabrinacsbaraini@gmail.com

Marcos Antonio Matiucci

ORCID: https://orcid.org/0000-0003-2053-2672 Universidade Estadual de Maringá, Brasil

E-mail:m.matiucci@hotmail.com

Ana Carolina Valente Junqueira de Castro

ORCID: https://orcid.org/0000-0001-8438-933X

Universidade Estadual de Maringá, Brasil

E-mail: caroldcastro586@gmail.com

Sabrina Martins dos Santos

ORCID: https://orcid.org/0000-0002-6658-688X

Universidade Estadual de Maringá, Brasil

E-mail: sabrina.martins.dos.santos@hotmail.com

Simone Siemer

ORCID: https://orcid.org/0000-0002-9052-5841

Universidade Estadual de Maringá, Brasil

E-mail: si_syemer@hotmail.com

Elenice Souza dos Reis Goes

ORCID: https://orcid.org/0000-0003-2437-4800 Universidade Federal da Grande Dourados, Brasil E-mail: elenicegoes@ufgd.edu.br

Maria Luiza Rodrigues de Souza

ORCID: https://orcid.org/0000-0001-5643-0841

Universidade Estadual de Maringá, Brasil

E-mail:mlrsouza@uem.br

\begin{abstract}
Resumo
A atividade pesqueira gera uma grande quantidade de resíduos, buscando diminuir os impactos ambientais, pode-se realizar o processamento da pele de peixe transformando em couro. O objetivo deste foi avaliar a resistência dos couros de tilápia do Nilo em cinco categorias de peso de abate, curtidos com tanino vegetal, assim como utilizar diferentes níveis de adição do tanino vegetal no processo de curtimento, para peles da maior categoria de peso. À medida que aumentou o peso de abate dos peixes, houve aumento na espessura $\left(\mathrm{Y}=0,745990+0,044832 \mathrm{X}, \mathrm{R}^{2}=88,27 \%\right)$, na resistência ao rasgamento progressivo $\left(\mathrm{Y}=0,735871+0,051553 \mathrm{X}, \mathrm{R}^{2}=81,16 \%\right)$, na tração $(\mathrm{Y}=10,508074$ $\left.1,847411 \mathrm{X}+0,664844 \mathrm{X}^{2}, \mathrm{R}^{2}=94,93 \%\right)$, no alongamento $\left(\mathrm{Y}=58,112121+5,110606 \mathrm{X}, \mathrm{R}^{2}=84,92 \%\right)$ e rasgamento progressivo ( $\mathrm{Y}=19,68836+7,800758 \mathrm{X}, \mathrm{R}^{2}=84,83 \%$ ), explicado pelas referidas equações. Para peles de peixes acima de $1 \mathrm{~kg}$ utilizou de $10 \%$ de tanino na etapa de curtimento e $4 \%$ no recurtimento e $12 \%$ e $2 \%$ de tanino, respectivamente para o curtimento e recurtimento. Os couros dessa categoria de tamanho apresentaram maior resistência a tração no sentido longitudinal. Quando analisado a distribuição das fibras colágenas finas e espessas quanto ao sentido do couro, notou-se que o couro de tilápia apresenta uma maior proporção de fibras finas $(62,40 \%)$ em relação a espessa $(37,60 \%)$, isto faz com que estas sejam amarradas mais intensamente, proporcionando maior resistência ao couro. As fibras finas
\end{abstract}


proporcionam uma melhor amarração da estrutura histológica desses couros, gerando uma maior resistência à tração, alongamento e rasgamento progressivo. Conclui-se que os couros acima de peixes acima de 1001g apresentam maior espessura e qualidade de resistência para serem utilizados na confecção.

Palavras-chave: Curtimento de pele; Fibras colágenas; Oreochromis niloticus.

\begin{abstract}
The fishing activity generates a large amount of waste, seeking to reduce environmental impacts, it is possible to process the fish skin transforming it into leather. The objective of this was to evaluate the resistance of Nile tilapia hides in five slaughter weight categories, tanned with vegetable tannin, as well as using different levels of addition of vegetable tannin in the tanning process, for skins of the highest weight category. As the slaughter weight of the fish increased, there was an increase in thickness $\left(\mathrm{Y}=0.745990+0.044832 \mathrm{X}, \mathrm{R}^{2}=88.27 \%\right)$, in progressive tear strength $(\mathrm{Y}=$ $\left.0.735871+0.051553 \mathrm{X}, \mathrm{R}^{2}=81.16 \%\right)$, in traction $\left(\mathrm{Y}=10.508074-1.847411 \mathrm{X}+0.664844 \mathrm{X}^{2}, \mathrm{R}^{2}=94.93 \%\right)$, in stretching $\left(\mathrm{Y}=58.112121+5.110606 \mathrm{X}, \mathrm{R}^{2}=84,92 \%\right)$ and progressive tearing $\left(\mathrm{Y}=19.68836+7.800758 \mathrm{X}, \mathrm{R}^{2}=84.83 \%\right)$, explained by the aforementioned equations. For fish skins above $1 \mathrm{~kg}, 10 \%$ tannin was used in the tanning step and $4 \%$ in the retanning step and $12 \%$ and $2 \%$ tannin, respectively, for the tanning and retanning. Leathers in this size category showed greater tensile strength in the longitudinal direction. When analyzing the distribution of fine and thick collagen fibers regarding the direction of the leather, it was noted that tilapia leather has a higher proportion of fine fibers $(62.40 \%)$ compared to thick $(37.60 \%)$, this makes so that these are tied more intensely, providing greater resistance to the leather. The fine fibers provide a better binding of the histological structure of these leathers, generating greater resistance to traction, stretching and progressive tearing. It is concluded that the hides above fish above $1001 \mathrm{~g}$ have greater thickness and strength quality to be used in confection.
\end{abstract}

Keywords: Collagen fibers; Oreochromis niloticus; Skin tanning.

\begin{abstract}
Resumen
La actividad pesquera genera una gran cantidad de residuos, buscando reducir los impactos ambientales, es posible procesar la piel del pescado transformándola en cuero. El objetivo de este fue evaluar la resistencia de las pieles de tilapia del Nilo en cinco categorías de peso de faena, curtidas con tanino vegetal, así como utilizar diferentes niveles de adición de tanino vegetal en el proceso de curtido, para pieles de la categoría de mayor peso. A medida que aumentó el peso de sacrificio del pescado, hubo un aumento en el grosor $\left(\mathrm{Y}=0,745990+0,044832 \mathrm{X}, \mathrm{R}^{2}=88,27 \%\right)$, en la resistencia al desgarro progresiva $\left(Y=0,735871+0,051553 X, R^{2}=81,16 \%\right)$, en la tracción $(Y=10.508074-1.847411 X$ $\left.+0.664844 \mathrm{X}^{2}, \mathrm{R}^{2}=94.93 \%\right)$, en estiramiento $\left(\mathrm{Y}=58.112121+5.110606 \mathrm{X}, \mathrm{R}^{2}=84,92 \%\right)$ y desgarro progresivo $(\mathrm{Y}=$ $19.68836+7.800758 \mathrm{X}, \mathrm{R}^{2}=84.83 \%$ ), explicado por las ecuaciones antes mencionadas. Para las pieles de pescado de más de $1 \mathrm{~kg}$, se utilizó un $10 \%$ de tanino en el paso de curtido y un $4 \%$ en el paso de recurtido y un $12 \%$ y $2 \%$ de tanino, respectivamente, para el curtido y recurtido. Los cueros de esta categoría de tamaño mostraron una mayor resistencia a la tracción en la dirección longitudinal. Al analizar la distribución de las fibras de colágeno finas y gruesas con respecto a la dirección del cuero, se observó que el cuero de tilapia tiene una mayor proporción de fibras finas $(62,40 \%)$ en comparación con las gruesas $(37,60 \%)$, esto hace que estas estén más atadas. intensamente, proporcionando una mayor resistencia al cuero. Las finas fibras proporcionan una mejor unión de la estructura histológica de estos cueros, generando mayor resistencia a la tracción, estiramiento y desgarro progresivo. Se concluye que los cueros de pescado por encima de los $1001 \mathrm{~g}$ tienen mayor espesor y calidad de resistencia para ser utilizados en repostería.
\end{abstract}

Palabras clave: Bronceado de la piel; Fibras de colágeno; Oreochromis niloticus.

\title{
1. Introdução
}

A espécies de peixe mais produzida na atualidade no Brasil é a Tilápia do Nilo (Oreochromis niloticus), representando $57 \%$ da produção do país, o estado do Paraná que garante a maior proporção dessa produção (Peixe BR, 2021). Este resultado é por causa das excelentes características zootécnicas das espécies, principalmente do seu rápido crescimento, adaptabilidade o clima, rusticidade e boa aceitação da ração comercial (Boscolo et al., 2001; Araujo \& Reynol, 2017). Mas, outro fator muito importante a ser considerado são as características tecnológicas da carne, tais como a coloração branca, de textura firme, sabor suave e não possui espinhas que forma um Y (SIMÕES et al., 2007) acima de tudo, com boas qualidades nutricionais, contendo

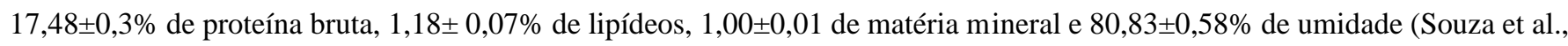
2020). Todavia, com o seu beneficiamento e forma de comercialização da carne em filé sem pele, uma elevada quantidade de resíduos é gerada. Kubitza (2006), no beneficiamento é gerado em torno de 72\% de resíduos, já outros autores mencionam 65\% do peso do peixe (Souza e Silva, 2005; Boscolo e Feiden, 2007), dos quais 4,5\% a 14\% representam a pele. Os autores mencionados essa variação no percentual de rendimento de filé e consequentemente dos resíduos gerados deve-se à vários 
fatores, tais como o tamanho do peixe no abate, fatores tecnológicos como o método de filetagem, destreza do filetador ou grau de mecanização da unidade de beneficiamento, entre outros. Conforme Prado et al. (2014) os resíduos do processo de beneficiamento são considerados um problema, devido à dificuldade de escoamento dos resíduos da linha de produção, estes por sua vez, acabam contribuindo com o impacto ambiental da atividade, sendo que a transformação do couro se trata de uma tecnologia bem difundida, pouco complexa e de fácil aplicação.

Diante disto, a utilização da pele para transformação em couro representa uma alternativa para a redução de resíduos gerados pela indústria de beneficiamento da tilápia. E o importante disso tudo é saber que com forme alguns autores a pele apresenta resistência para aplicação na confecção (Hilbig et al., 2013; Neu et al., 2015).

Vários estudos foram realizados mostrando que vários aspectos influenciam a qualidade dos couros ao término do curtimento. Dentre eles, a idade, peso de abate ou tamanho, espécie e estrutura ou arquitetura histológica, a orientação e disposição das fibras colágenas distribuídas no sentido longitudinal ou transversal (Souza, 2004; Hilbig,et al., 2013; Neu et al., 2015). A metodologia utilizada para o curtimento também pode influenciar na resistência (agente curtente, produtos químicos, tempo aplicado nas etapas do processo) (Franco et al., 2013; Neu et al., 2015; Prado et al., 2014). Diante desta diversidade, há necessidade de adequação das técnicas de curtimento, visando o melhor aproveitamento das peles de tilápia para transformação em couros e sua utilização na confecção. E com a preocupação de agregar valor e reduzir os resíduos na cadeia produtiva da tilápia, o presente estudo teve como objetivo foi realizar um estudo qualitativo, Pereira et al. (2018) e avaliou a resistência de couros de tilápia de diferentes categorias de peso submetidos ao curtimento com tanino vegetal, assim com as alterações em alguns percentuais de utilização de tanino vegetal nas etapas de curtimento e recutimento para as peles provenientes de peixes de maior peso corporal.

\section{Metodologia}

Para realização do experimento, foram utilizadas peles de tilápia do Nilo, provenientes da indústria de beneficiamento de pescado Abatedouro de Peixes Sol Nascente Ltda, localizado na cidade de Mandaguaçu- PR e do abatedouro Bom futuro indústria e comércio de peixe localizado em Cuiabá- MT. Foram realizados dois ensaios, sendo Ensaio I - Avaliação da resistência dos couros de Tilápia do Nilo curtidas com tanino vegetal de acordo com a categoria de peso de abate e Ensaio II Avaliação de efeito do percentual de tanino vegetal utilizado na etapa de curtimento/recurtimento e sentido de corte dos corpos de provas de couros de tilápia abatidas com peso acima de 1,001g.

Para o Ensaio I - Foram utilizadas 200 unidades distribuídas em quatro categorias de peso, categoria (1) P1= até 600 g, categoria (2) P2= de 601 a $700 \mathrm{~g}$ e categoria (3) P3= de 701 a 800g e categoria (4) P4= 801g a 1000g e categoria (5) P5= acima de 1001g.

Para o Ensaio II - Foram utilizadas 120 unidades de peles abatidas com peso corporal acima de 1000g, sendo distribuídas nos três tratamentos descritos a seguir (Quadro 1):

Quadro 1. Etapas do processo de curtimento.

\begin{tabular}{|l|l|l|}
\hline \multirow{2}{*}{$\begin{array}{l}\text { Trata } \\
\text { mentos }\end{array}$} & \multicolumn{2}{|c|}{ Etapas do Processo de curtimento } \\
\cline { 2 - 3 } & \multicolumn{1}{|c|}{ Curtimento } & \multicolumn{1}{c|}{ Recurtimento } \\
\hline Trat 1 & $10 \%$ de tanino vegetal Weibull@ & $4 \%$ de tanino vegetal Weibull@ \\
\hline Trat 2 & $12 \%$ de tanino vegetal Weibull & $2 \%$ de tanino vegetal Weibull \\
\hline Trat 3 & $14 \%$ de tanino vegetal Weibull & $0 \%$ de tanino vegetal Weibull \\
\hline
\end{tabular}

Fonte: Autores. 
Antes do abate, 24 horas, os peixes foram depurados em tanques de alvenaria a realização do abate eles foram submetidos a choques térmicos água $\left(-5^{\circ} \mathrm{C}\right)$, descamados, lavados e pesados em balança de precisão de $0,1 \mathrm{~g}$, após foram filetados.

A filetagem foi realizada em série, por apenas um funcionário treinado do abatedouro, conforme a metodologia empregada pela indústria. Depois da filetagem foram retiradas as peles dos filés, utilizando o equipamento SKINZIT®3000. O material foi identificado de acordo com a classificação de peso para serem curtidas.

\section{Processo de curtimento das peles}

ENSAIO I -O curtimento das peles foi efetuado como descrito por Souza et al. (2002) e Souza (2007) com algumas modificações através das seguintes etapas: remolho, descarne, caleiro (3\% de soba barrilha leve e 3\% de cal hidratada), desencalagem, purga, desengraxe, piquel ( $2 \%$ ácido fórmico para atingir $\mathrm{pH} 4,0)$, curtimento ( $12 \%$ de tanino vegetal da marca Weibull $®)$, basificação, neutralização (1,5\% bicarbonato de sódio, cada etapa), recurtimento e tingimento (4\% de vegetalweibull@) (Figura 1), engraxe ( $8 \%$ óleos, superderma MK ®), Fixação (2\% ácido fórmico), Secagem (Figura 2) e Amaciamento.

Figura 1. Etapas do processamento do curtimento. A) Caleiro, B) Desencalagem, C) Piquel, D) Curtimento e E) Recurtimento.

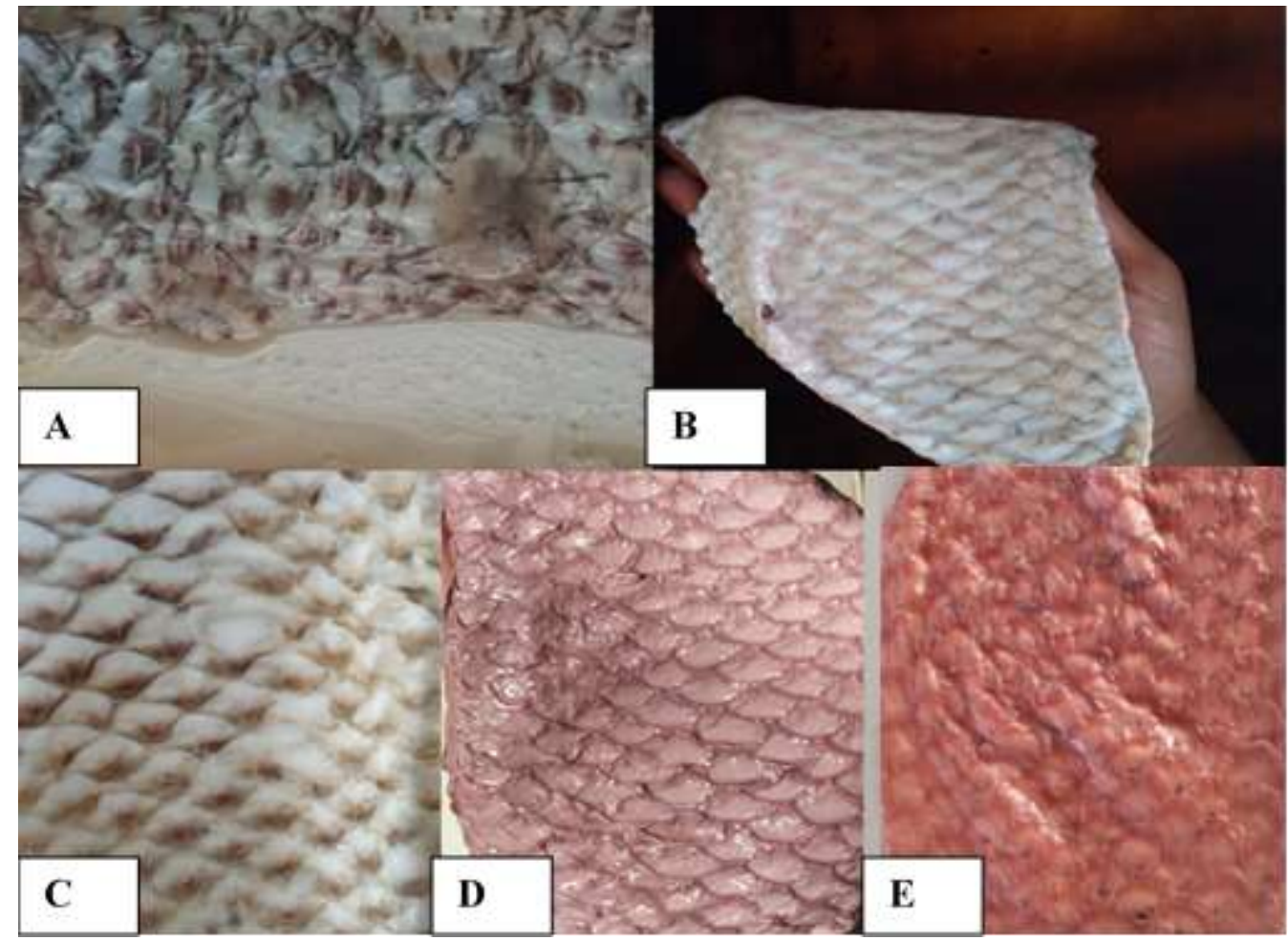

Fonte: Autores.

ENSAIO II - O mesmo procedimento descrito anteriormente, alterando o curtimento e recurtimento, com utilização no Trat $1-10 \%$ e $4 \%$ tanino vegetal da marca Weibul1® , Trat 2 - $12 \%$ e $2 \%$ de tanino vegetal da marca Weibull@ e Trat 3 - $14 \%$ e $0 \%$ tanino vegetal da marca Weibull ${ }^{\circ}$, respectivamente. 
Figura 2. Secagem dos couros.

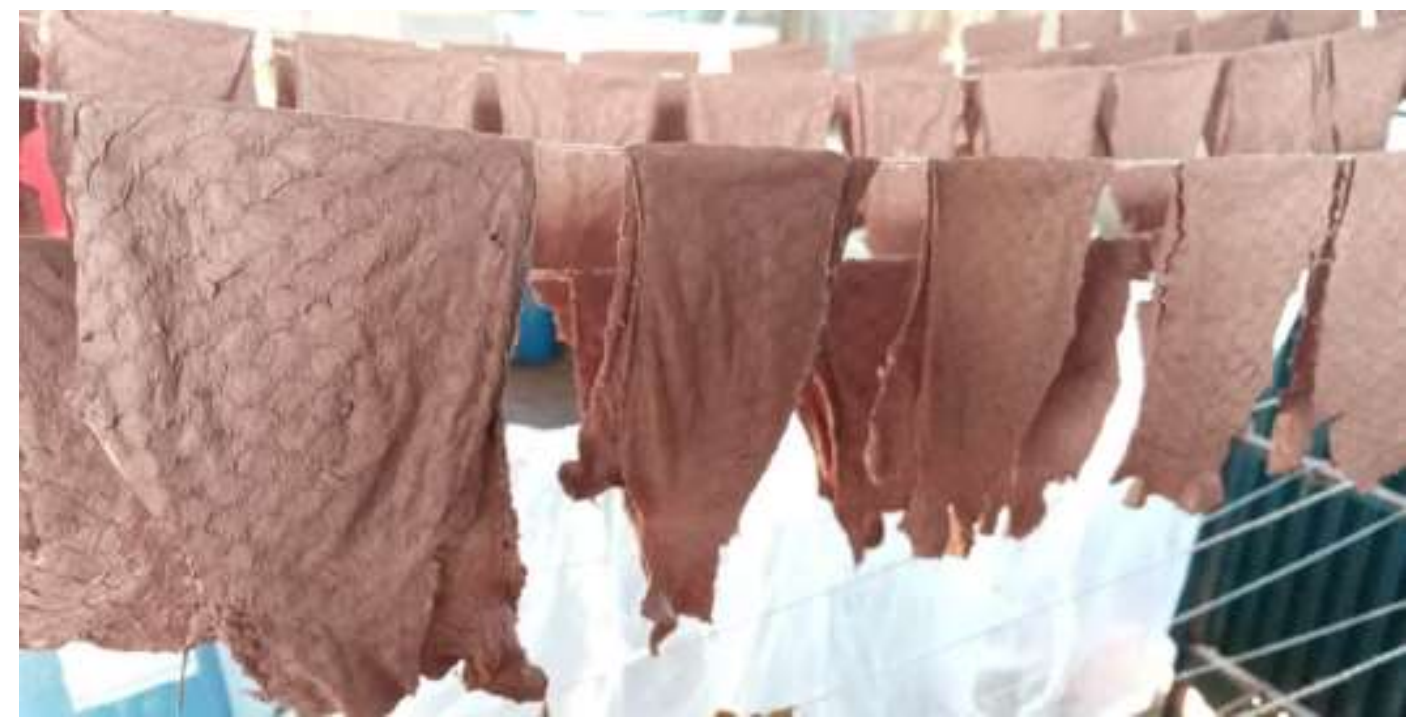

Fonte: Autores.

\section{Obtenção dos corpos-de-provas para os testes físico-mecânicos do couro}

Como não existem normas específicas para realização dos testes dos couros de peixes, foram estabelecidos determinados parâmetros, quanto ao local e posição dos cortes e número de amostragens, baseados em trabalhos já realizados (Souza et al., 2004; Souza et al., 2006a; Souza et al., 2006b; Vieira et al., 2008; Godoy et al., 2010; Franco et al., 2013a; Franco et al., 2013b; Souza te al., 2017)

Foram retirados os corpos de prova $(n=10)$ no sentido longitudinal ao comprimento do corpo do peixe, foi utilizado balancim e facas de corte específicas para determinação da tração e alongamento e rasgamento progressivo (Ensaio I), como a metodologia de Franco et al. (2013b) (Figura 3A), para o ensaio II foram retirados dois corpos de prova de 10 couros (n=10) no sentido longitudinal e dois corpos de prova em 10 couros $(n=10)$ no sentido transversal, conforme Godoy et al. (2010) (Figura 3B). 
Figura 3. Retirada dos corpos de prova do couro de tilápia: A) no sentido longitudinal. Fonte: Franco et al. (2013b) e B) no sentido longitudinal e transversal do couro referente ao comprimento do corpo do peixe.

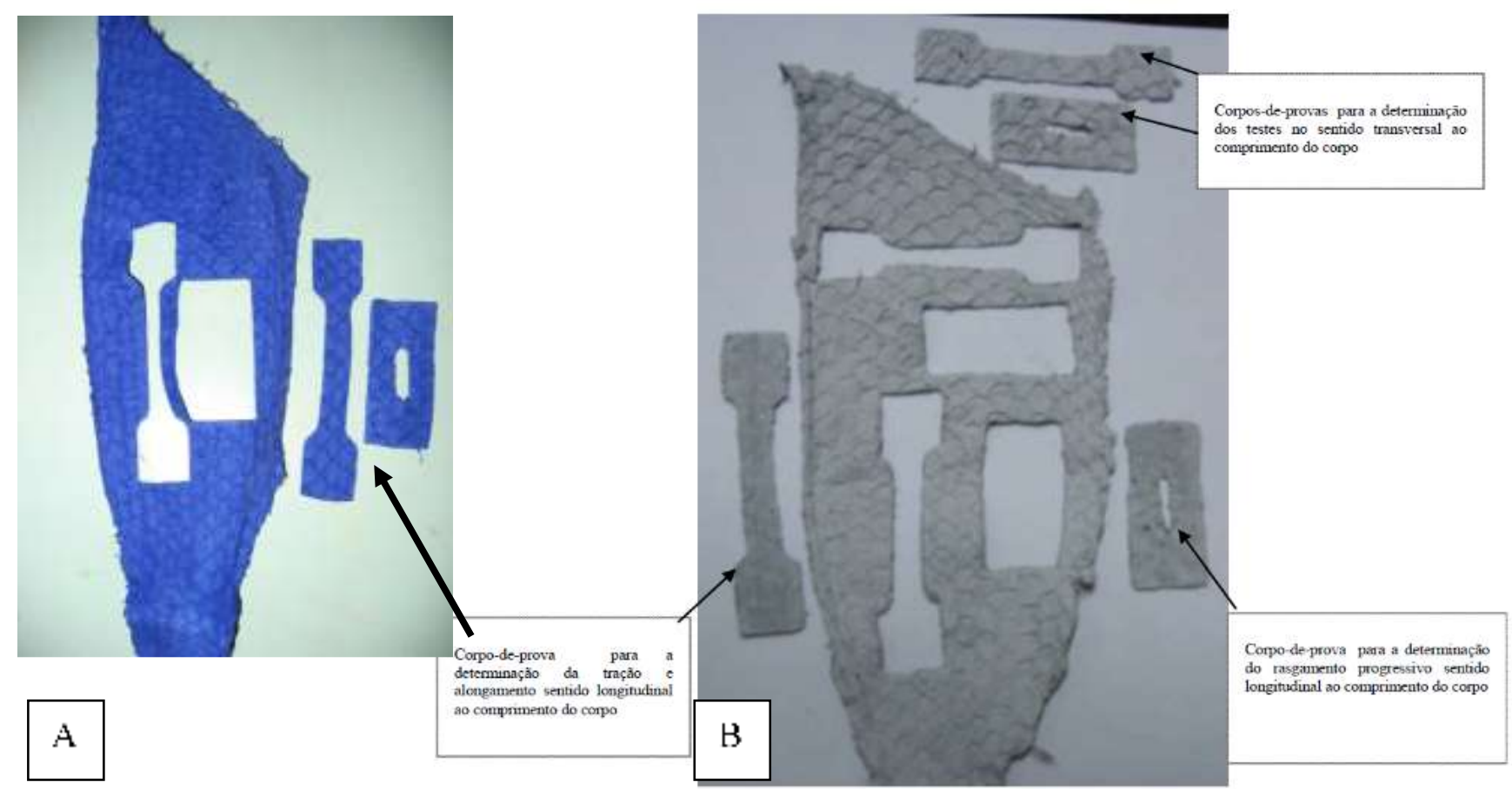

Fonte: Godoy et al., (2010).

Os testes realizados foram de tração e alongamento (ABNT - NBR ISSO 3376, 2014) e o de rasgamento progressivo (ABNT - NBR ISO 3377-2, 2014). Foi determinado as espessuras de cada amostra para o cálculo dos testes com auxílio de um espessímetro (ABNT - NBR 2589, 2016). Após as amostras foram levadas para um ambiente climatizado em torno de $23 \pm 2^{\circ} \mathrm{C}$ e umidade relativa do ar de $50 \pm 5 \%$, por 48 h conforme ABNT - NBR 10455, 2021). Para os testes mecânicos foi utilizado o dinamômetro da marca EMIC, com velocidade de $100 \pm 10 \mathrm{~mm} / \mathrm{min}$. A célula de carga utilizada no dinamômetro foi de $200 \mathrm{kgf}$. A calibração foi realizada pela Emic-Dcame, laboratório de calibração credenciado pela Cgcre/Inmetro sob n ${ }^{\circ} 197$.

\section{Testes físico-mecânicos do couro}

As amostras foram preparadas para a análise físico-química seguindo as condições exigidas pelas normas da ABNT (NBR ISSO 16511:2016). Foram realizadas analises de determinação das substâncias extraídas em diclorometano (ABNT- NBR 11030, 2020), pH e cifra diferencial (ABNT NBR 11057, 2020). 
Figura 4. A) Realização dos testes rasgamento progressivo e B) dados apresentados pelo software acoplado ao dinamômetro.

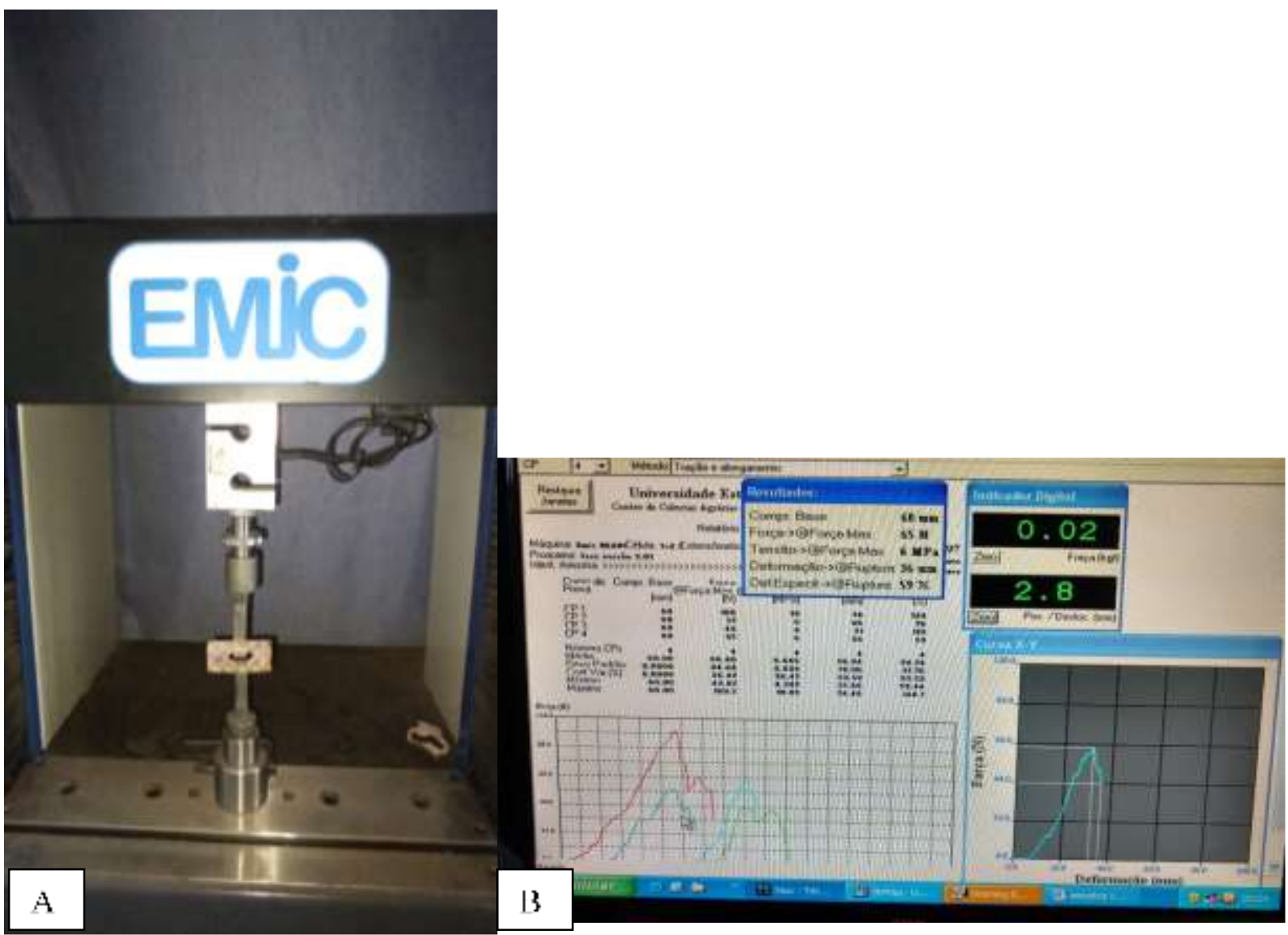

Fonte: Autores.

\section{Delineamento estatístico}

Para o Ensaio I foi utilizado um delineamento experimental inteiramente ao acaso, com cinco tratamentos, com 10 repetições por tratamento, sendo o couro a unidade experimental. Os resultados foram submetidos à análise de variância e realizada uma regressão ao nível de $5 \%$ de probabilidade sob as categorias de peso dos peixes ao abate, utilizando o programa Statistical Analysis System (SAS, SAS Inst. Inc. Cary, NC, USA).

Para o Ensaio II foi um delineamento inteiramente casualizado, em esquema fatorial 3x2, sendo técnica três técnicas (Trat $1=10 \%$ e $4 \%$ tanino vegetal da marca Weibull ${ }^{\circledR}$, Trat $2=12 \%$ e $2 \%$ tanino vegetal da marca Weibull@ e Trat $3=14 \%$ e $0 \%$ tanino vegetal da marca Weibull ${ }^{\circledR}$, respectivamente para o curtimento e recurtimento dos couros) e dois sentidos do couro (Sent 1= Longitudinal e Sent 2= transversal).

\section{Resultados e Discussão}

Através da determinação da classificação do peso de abate dos peixes é possível predizer o tamanho dos couros para uso na confecção. Segundo Larezzi (1988), afirma que há décadas o maior problema enfrentado é a industrialização na comercialização é quanto ao pequeno tamanho, em por causa da competitividade com outras peles exóticas existentes no mercado. Após o curtimento das peles, estas foram medidas para determinação do tamanho das mesmas, para facilitar a sua aplicabilidade e possibilidade de comercialização, cuja classificação consta a seguir:

- $\quad \mathrm{CP} 1=$ até $600 \mathrm{~g}, 19,0 \mathrm{~cm}$ de comprimento $\times 6,0 \mathrm{~cm}$ de largura.

- $\quad \mathrm{CP} 2=$ de 601 a $700 \mathrm{~g}, 20 \mathrm{~cm}$ de comprimento $\times 6,2 \mathrm{~cm}$ de largura. 
- $\quad \mathrm{CP} 3=$ de 701 a $800 \mathrm{~g}, 21 \mathrm{~cm}$ de comprimento $\times 6,6 \mathrm{~cm}$ de largura.

- $\quad \mathrm{CP} 4=$ de 801 a $1000 \mathrm{~g}, 22 \mathrm{~cm}$ de comprimento $\times 7,5 \mathrm{~cm}$ de largura.

- $\quad \mathrm{CP} 5=$ acima de $1001 \mathrm{~g}, 24,4 \mathrm{~cm}$ de comprimento $\times 8,2 \mathrm{~cm}$ de largura.

Esta classificação facilita a comercialização, pois assim sabe-se o tamanho estimado do couro através do seu comprimento e largura.

$\mathrm{O}$ teste de tração e alongamento aponta que houve diferenças significativas, nas diferentes categorias de pesos para todos os parâmetros analisados (Tabela 1). Os resultados a tração e alongamento, conforme aumentou o peso do peixe ao abate, houve um aumento na espessura, sendo explicado pela equação linear positiva $Y=0,745990+0,044832 X\left(R^{2}=88,27 \%\right)$, o mesmo observado para o alongamento, ou a elasticidade do couro, entretanto, para esta variável os três pesos inferiores apresentaram estatisticamente porcentagens de alongamento semelhantes, o aumento só começou a ser observado após o CP4 (801 a 1000g), o que é explicado pela equação $\mathrm{Y}=58,112121+5,110606 \mathrm{X}\left(\mathrm{R}^{2}=84,92 \%\right)$ (Tabela 1).

Tabela 1. Tração e alongamento em diferentes categorias de pesos ao abate curtidas com tanino vegetal.

\begin{tabular}{lccccc}
\hline Couros & Espessura $(\mathrm{mm})$ & $\begin{array}{c}\text { Força Máxima a } \\
\text { ruptura } \\
(\mathrm{N})\end{array}$ & $\begin{array}{c}\text { Deformação } \\
(\mathrm{mm})\end{array}$ & Alongamento $(\%)$ & $\begin{array}{c}\text { Tração } \\
\left(\mathrm{N} / \mathrm{mm}^{2}\right)\end{array}$ \\
\hline $\mathrm{CP} 1^{1}$ & $0,77 \pm 0,09^{2}$ & $53,83 \pm 48,92$ & $40,25 \pm 6,22$ & $67,17 \pm 5,86$ & $8,17 \pm 4,02$ \\
$\mathrm{CP} 2$ & $0,87 \pm 0,01$ & $93,14 \pm 9,61$ & $39,71 \pm 6,76$ & $66,28 \pm 6,75$ & $12,60 \pm 0,41$ \\
$\mathrm{CP} 3$ & $0,87 \pm 0,01$ & $80,41 \pm 22,34$ & $42,75 \pm 3,72$ & $66,25 \pm 6,78$ & $8,97 \pm 3,22$ \\
$\mathrm{CP} 4$ & $0,93 \pm 0,07$ & $108,83 \pm 6,08$ & $45,00 \pm 1,47$ & $74,58 \pm 1,55$ & $13,93 \pm 1,74$ \\
$\mathrm{CP} 5$ & $0,98 \pm 0,12$ & $166,78 \pm 64,03$ & $61,11 \pm 14,64$ & $84,22 \pm 11,19$ & $17,08 \pm 4,89$ \\
\hline Valor P & $0,0001^{4}$ & $<0,0001^{4}$ & $<0,0001^{4}$ & $0,0002^{4}$ & $<0,0001^{4}$ \\
\hline C.V ${ }^{3} .(\%)$ & 10,65 & 24,56 & 12,88 & 18,17 & 24,02 \\
\hline
\end{tabular}

${ }^{1} \mathrm{CP} 1=$ até $600 \mathrm{~g}, \mathrm{CP} 2=$ de 601 a $700 \mathrm{~g}, \mathrm{CP} 3=$ de 701 a $800 \mathrm{~g}, \mathrm{CP} 4=801$ a $1000 \mathrm{~g}$ e CP5= acima de 1001 g. ${ }^{2}$ Médias \pm desvio padrão; ${ }^{3} \mathrm{C} . \mathrm{V} .=$ Coeficiente de Variação. 4Equações de regressão consta na Tabela 3. Fonte: Autores.

Ao analisar o alongamento (\%) de diferentes espécies de peixes, curtidos com sais de cromo, Yoshida et al. (2016) observaram valores médios de 108,43\% para couro de tilápia do Nilo e 111,00\% para couro de salmão, apresentando elasticidade superior ao deste experimento, enquanto os autores relataram valores menores para o couro de cachara $(58,93 \%)$. Isto também pode estar relacionado ao processo de curtimento, assim como, a espécie de peixe, em função da arquitetura histológica dessas peles (Prado et al., 2014; Yoshida et al., 2016; Souza et al., 2017).

Hilbig et al. (2013) avaliaram o couro de tilápia do Nilo curtido com tanino vegetal. Os autores utilizaram 10\% de tanino vegetal na etapa de curtimento e no recurtimento $1 \%$ de tanino sintético e $2 \%$ de tanino vegetal. Os couros apresentaram uma espessura de $0,99 \mathrm{~mm}$ para o sentido longitudinal e 0,88 para o transversal, cujos valores apresentados estavam dentro da espessura obtidos nos couros das diferentes categorias analisadas neste experimento. Os autores também relataram que os couros apresentaram elevada resistência na tração (10,87 a 20,94 N/mm2), uma elasticidade média de 94,46\% e não houve diferença para o rasgamento progressivo $(54,13$ a $58,62 \mathrm{~N} / \mathrm{mm})$. Os resultados obtidos de tração e alongamento deste experimento foram inferiores a relatados por Hilbig et al. (2013), podendo isto estar diretamente ao curtimento.

Os parâmetros de força máxima na ruptura, deformação e tração apresentaram o mesmo comportamento em relação às diferentes categorias de pesos ao abate, com um efeito quadrático, cujas equações foram $Y=73,075758-14,874923 X+6,896722 X^{2}$ $\left(\mathrm{R}^{2}=90,59 \%\right)$ para força, $\mathrm{Y}=49,422727-8,797511 \mathrm{X}+2,166126 \mathrm{X}^{2}\left(\mathrm{R}^{2}=97,20 \%\right)$ para deformação e $\mathrm{Y}=10,508074-$ 
$1,847411 X+0,664844 X^{2}\left(R^{2}=94,93 \%\right)$ para tração (Tabela 1).

Os resultados da Tabela 2, mostram que houve diferenças significativas para espessura do couro, força máxima e rasgo.

Tabela 2. Rasgamento progressivo de couros de tilápias do Nilo em diferentes categorias de pesos curtidas com tanino vegetal.

\begin{tabular}{lccc}
\hline \multicolumn{1}{c}{ Couros } & Espessura $(\mathrm{mm})$ & Força Máxima $(\mathrm{N})$ & Rasgo $(\mathrm{N} / \mathrm{mm})$ \\
\hline $\mathrm{CP} 1^{1}$ & $0,78 \pm 0,11^{2}$ & $25,45 \pm 17,93$ & $31,75 \pm 16,72$ \\
$\mathrm{CP} 2$ & $0,84 \pm 0,05$ & $38,66 \pm 4,72$ & $43,90 \pm 4,57$ \\
$\mathrm{CP} 3$ & $0,88 \pm 0,01$ & $39,33 \pm 4,05$ & $46,00 \pm 2,47$ \\
$\mathrm{CP} 4$ & $0,92 \pm 0,03$ & $44,58 \pm 1,20$ & $52,95 \pm 4,48$ \\
$\mathrm{CP} 5$ & $1,02 \pm 0,04$ & $67,42 \pm 24,04$ & $66,32 \pm 17,85$ \\
\hline Valor de P. & $<0,0001^{4}$ & $<0,0001^{4}$ & $0,0004^{4}$ \\
\hline C. ${ }^{3} .(\%)$ & 10,37 & 20,56 & 16,35 \\
\hline
\end{tabular}

${ }^{1} \mathrm{CP} 1=$ até $600 \mathrm{~g}, \mathrm{CP} 2=$ de 601 a $700 \mathrm{~g}, \mathrm{CP} 3=$ de 701 a $800 \mathrm{~g}, \mathrm{CP} 4=801$ a $1000 \mathrm{~g}$ e CP5= acima de 1001 g. ${ }^{2}$ Médias \pm desvio padrão; ${ }^{3} \mathrm{C} . \mathrm{V} .=$ Coeficiente de Variação. ${ }^{4}$ Equações de regressão consta na Tabela 3. Fonte: Autores.

As espessuras dos couros apresentaram o mesmo comportamento aos relatados para o teste de tração e alongamento. Conforme aumentou o peso ao abate houve aumento na espessura do couro quando analisado para a determinação do rasgamento progressivo, cuja equação linear positiva $Y=0,735871+0,051553 X\left(R^{2}=81,16 \%\right)$ descreve esses resultados. Os resultados obtidos para espessura dos couros nos cortes dos corpos de prova para análise de tração e alongamento e rasgamento progressivo foram muito semelhantes (Tabela 1 e Tabela 2). Mostrando que a espessura na área do couro como um todo apresentava-se homogêneo.

Tabela 3. Equações de regressão dos parâmetros avaliados dos couros de tilápias do Nilo em diferentes categorias de pesos ao abate curtidas com tanino vegetal

\section{Parâmetros avaliados}

\begin{tabular}{|c|c|c|}
\hline $\begin{array}{l}\text { Espessura (mm) analisada na Determinação de Tração e } \\
\text { alongamento }\end{array}$ & $Y=0,745990+0,044832 X$ & $\left.\mathrm{R}^{2}=88,27 \%\right)$ \\
\hline Alongamento $(\%)$ & $Y=58,112121+5,110606 X$ & $\mathrm{R}^{2}=84,92 \%$ \\
\hline Força máxima na ruptura $(\mathrm{N})$ & $Y=73,075758-14,874923 X+6,896722 X^{2}$ & $\mathrm{R}^{2}=90,59 \%$ \\
\hline Deformação (mm) & $Y=49,422727-8,797511 X+2,166126 X^{2}$ & $\mathrm{R}^{2}=97,20 \%$ \\
\hline Tração $\left(\mathrm{N} / \mathrm{mm}^{2}\right)$ & $Y=10,508074-1,847411 X+0,664844 X^{2}$ & $\mathrm{R}^{2}=94,93 \%$ \\
\hline $\begin{array}{l}\text { Espessura }(\mathrm{mm}) \text { analisada na Determinação do Rasgamento } \\
\text { progressivo }\end{array}$ & $Y=0,735871+0,051553 X$ & $\mathrm{R}^{2}=81,16 \%$ \\
\hline $\begin{array}{l}\text { Força máxima aplicada no teste de determinação do rasgamento } \\
\text { progressivo }\end{array}$ & $Y=19,68836+7,800758 X$ & $\mathrm{R}^{2}=84,83 \%$ \\
\hline Rasgo (N/mm) & $Y=30,155417+6,010917 X$ & $\mathrm{R}^{2}=86,01 \%$ \\
\hline
\end{tabular}

Fonte: Autores. 
A força máxima aplicada e a determinação do rasgo, também, apresentaram um comportamento linear positivo, quanto maior o peso do peixe, de onde a pele foi retirada para a produção do couro, maior foi a resistência do couro, sendo explicados pelas equações $Y=30,155417+6,010917 X\left(R^{2}=86,01 \%\right)$ para o rasgo e $Y=19,68836+7,800758 X\left(R^{2}=84,83 \%\right)$ para a força máxima.

Uzeika (1999) afirma que a espessura da pele dos peixes pode variar muito e essa variação está relacionada não só com a espécie e diferentes regiões do corpo, como também, o habitat do animal. Da mesma forma pode inferir que a espessura da pele está em função do tamanho do peixe, onde em peixes menores, suas peles devem apresentar uma espessura mais homogênea às peles de peixes maiores. Isto ocorre de acordo com o seu desenvolvimento, onde a medida que vão crescendo, vai ocorrendo uma superposição de camadas de fibras colágenas, podendo ser desigual nas diferentes regiões da pele do peixe. Em bovinos ocorre um desenvolvimento maior na espessura na região do grupão que corresponde ao dorso do animal e depois vai intensificando a sobreposição de fibras colágenas nas regiões dos flancos, à medida que o animal vai se tornando adulto (Hoinacki, 1989).

De acordo com Rocha et al. (2020) à medida que aumenta o tamanho dos couros também ocorre um aumento na espessura do mesmo. Segundo Silva (2012) o tamanho do peixe é um dos fatores que está diretamente relacionado com a espessura da pele, sendo que à medida que o peixe cresce ocorre um aumento na espessura da pele, refletido pela quantidade de sobreposição das fibras colágenas. E são essas fibras que irão reagir com os agentes curtentes, dando a característica de resistência ao couro. Além dessa sobreposição das fibras em camadas cruzadas, ainda estas são entrelaçadas entre si no sentido transversal à superfície do couro, determinando dessa forma uma maior resistência ao couro após o seu curtimento (Souza et al., 2004; Souza et al. 2006). Também Franco et al (2013) afirmam que a resistência do couro de tilápia do Nilo deve-se primeiramente à estrutura histológica da pele ou a arquitetura dos feixes de fibras colágenas na derme. Isto em função desse arranjo de camadas de feixes de fibras colágenas sobrepostas paralelamente à superfície da pele e intercaladas perpendicularmente a essa camada, formando uma verdadeira amarração entre essas fibras colágenas, proporcionando uma maior resistência ao couro curtido.

Rocha et al. (2020) não observaram diferença na qualidade de resistência (tração, deformação e alongamento) dos couros de tilápias quando classificados por tamanho (trat $1=$ pequeno $- \pm 16,5 \mathrm{~cm} \mathrm{x} \pm 5,4 \mathrm{~cm}$; trat $2=$ médio $- \pm 18,5 \mathrm{~cm} \mathrm{x} \pm 6,0 \mathrm{~cm}$ e trat $3=$ grande $- \pm 20,5 \mathrm{~cm} \times \pm 8 \mathrm{~cm}$, respectivamente para comprimento e largura do couro). Mas, os autores afirmam que talvez em outra classificação de tamanho dos couros, estes teriam apresentado diferenças na força aplicada na ruptura do corpo de prova, afetando consequentemente na qualidade de resistência para esses parâmetros que avaliaram. Fato que realmente ocorreu neste experimento, onde foram utilizados uma variação maior no tamanho dos couros em função de seus respectivos pesos de abate.

Os couros menores (16,5 cm comprimento x 5,4 cm de largura) avaliados por Rocha et al. (2020) apresentaram significativamente menor resistência ao rasgamento progressivo $(47,13 \mathrm{~N} / \mathrm{mm})$ e força aplicada $(36,60 \mathrm{~N})$ neste teste, quando comparados com os couros de tamanhos médios (18,5 cm comprimento x $6,0 \mathrm{~cm}$ largura) que foi de $62,18 \mathrm{~N} / \mathrm{mm}$ e 48,60N. Mas, os autores relataram que os de tamanho médio não diferiram dos couros grandes $(20,5 \mathrm{~cm}$ comprimento x $8 \mathrm{~cm}$ largura), para o rasgamento $(73,04 \mathrm{~N} / \mathrm{mm})$ e para a força $(58,30 \mathrm{~N})$. Os autores recomendam curtir peles maiores por apresentar maior comprimento e largura, com maior potencial para sua aplicação, além de observar que elas apresentam uma maior resistência comparadas aos couros menores que $16,5 \mathrm{~cm}$ de comprimento e $4 \mathrm{~cm}$ de largura, além de apresentarem significativamente menor espessura $(0,62 \mathrm{~mm}$ ) em comparação aos maiores (acima de 18,5 $\mathrm{cm}$ de comprimento e $6,0 \mathrm{~cm}$ largura) que apresentam uma espessura superior $(0,77 \mathrm{~mm})$ e maior resistência. Estes valores apresentados por Rocha et al. (2020) foram superiores aos resultados obtidos nesse trabalho de pesquisa. Mas, talvez estes resultados estejam relacionados com a técnica de curtimento, pois já visto que isto é um motivo para interferir muito na resistência dos couros. 
Ensaio II - Avaliação de efeito do percentual de tanino vegetal utilizado na etapa de curtimento/recurtimento e sentido de corte dos corpos de provas de couros de tilápia abatidas com peso acima de 1,001g.

Após o curtimento de todos os couros dentro dessa categoria de peso de abate (acima de 1001g) e quantidade de tanino vegetal utilizado no processo, foram realizadas as medições para avaliar o comprimento e largura dos couros. Pode-se observar que a variação entre as medidas dentro da categoria de peso foi de $0,5 \mathrm{~cm}$ para comprimento e $0,85 \mathrm{~cm}$ para largura.

- Trat $1=10 \%$ tanino $=$ acima de $1001 \mathrm{~g}, 24,6 \mathrm{~cm}$ de comprimento $\mathrm{x} 7,7 \mathrm{~cm}$ de largura.

- Trat $2=12 \%$ tanino $=$ acima de $1001 \mathrm{~g}, 24,5 \mathrm{~cm}$ de comprimento $\mathrm{x} 8,55 \mathrm{~cm}$ de largura.

- Trat $3=14 \%$ tanino $=$ acima de $1001 \mathrm{~g}, 24,1 \mathrm{~cm}$ de comprimento $\mathrm{x} 8,25 \mathrm{~cm}$ de largura.

Os resultados mostram que houve efeito de interação, entre a concentração de tanino utilizado no curtimento o com o sentido avaliado, para as espessuras, força, deformação e tração. Não houve interação apenas para o alongamento, entretanto, quando observado as concentrações de tanino e o sentido isoladamente dentro desta variável, eles apresentaram diferenças significativas, sendo que a concentração de $14 \%$ de tanino e o sentido longitudinal apresentaram os maiores alongamentos, $81,07 \%$ e $83,63 \%$, respectivamente (Tabela 4 ).

Tabela 4. Tração e alongamento de couros de tilápias do curtidos com diferentes concentrações de taninos analisados nos sentidos longitudinal e transversal.

\begin{tabular}{|c|c|c|c|c|c|c|}
\hline \multicolumn{2}{|c|}{$\begin{array}{l}\text { Couros de } \\
\text { tilápia do Nilo }\end{array}$} & Espessura (mm) & $\begin{array}{l}\text { Força } \\
(\mathrm{N})\end{array}$ & $\begin{array}{c}\text { Deformação } \\
(\mathrm{mm})\end{array}$ & $\begin{array}{c}\text { Alongamento } \\
(\%)\end{array}$ & Tração $\left(\mathrm{N} / \mathrm{mm}^{2}\right)$ \\
\hline \multirow[t]{2}{*}{$10 \%$ tanino } & Longitudinal & $1,05 \pm 0,01^{\mathrm{ab}}$ & $155,93 \pm 44,80^{a}$ & $58,40 \pm 17,24^{\mathrm{a}}$ & $93,80 \pm 23,21$ & $15,59 \pm 3,11^{\mathrm{a}}$ \\
\hline & Transversal & $1,07 \pm 0,02^{\mathrm{ab}}$ & $82,33 \pm 28,80^{c}$ & $32,60 \pm 8,56^{\mathrm{b}}$ & $68,33 \pm 2,26$ & $9,21 \pm 3,27^{b}$ \\
\hline \multirow[t]{2}{*}{$12 \%$ tanino } & Longitudinal & $0,87 \pm 0,18^{b}$ & $108,83 \pm 2,30^{\mathrm{b}}$ & $45,00 \pm 3,84^{\mathrm{ab}}$ & $75,00 \pm 4,41$ & $18,07 \pm 5,59^{a}$ \\
\hline & Transversal & $1,14 \pm 0,09^{\mathrm{a}}$ & $127,30 \pm 16,17^{\mathrm{ab}}$ & $27,40 \pm 13,76^{\mathrm{b}}$ & $52,50 \pm 18,09$ & $9,31 \pm 3,17^{b}$ \\
\hline \multirow[t]{2}{*}{$14 \%$ tanino } & Longitudinal & $1,12 \pm 0,07^{\mathrm{a}}$ & $90,72 \pm 20,41^{b c}$ & $42,72 \pm 1,56^{\mathrm{ab}}$ & $79,18 \pm 8,59$ & $9,53 \pm 2,95^{\mathrm{b}}$ \\
\hline & Transversal & $1,03 \pm 0,02^{\mathrm{ab}}$ & $98,67 \pm 12,46^{\mathrm{bc}}$ & $36,50 \pm 4,66^{\mathrm{b}}$ & $47,17 \pm 23,42$ & $12,47 \pm 0,01^{\mathrm{ab}}$ \\
\hline \multicolumn{7}{|c|}{ Efeitos principais } \\
\hline \multirow[t]{3}{*}{ Tanino } & $10 \%$ & $1,06 \pm 0,01$ & $119,13 \pm 8,00$ & $45,50 \pm 4,34$ & $62,47 \pm 8,12^{b}$ & $12,40 \pm 0,08$ \\
\hline & $12 \%$ & $0,99 \pm 0,06$ & $117,22 \pm 6,09$ & $37,00 \pm 4,16$ & $64,77 \pm 5,82^{\mathrm{b}}$ & $14,09 \pm 1,61$ \\
\hline & $14 \%$ & $1,08 \pm 0,03$ & $94,87 \pm 16,26$ & $39,48 \pm 1,68$ & $81,07 \pm 10,48^{\mathrm{a}}$ & $11,06 \pm 1,42$ \\
\hline \multirow[t]{2}{*}{ Sentido } & Longitudinal & $1,01 \pm 0,04$ & $122,18 \pm 11,05$ & $49,63 \pm 8,47$ & $83,63 \pm 13,63^{a}$ & $14,62 \pm 2,14$ \\
\hline & Transversal & $1,08 \pm 0,03$ & $99,78 \pm 11,35$ & $32,44 \pm 8,72$ & $57,19 \pm 13,40^{\mathrm{b}}$ & $10,29 \pm 2,19$ \\
\hline \multicolumn{7}{|l|}{ Probabilidades } \\
\hline Tanino $(\mathrm{T})$ & & 0,0751 & 0,1073 & 0,1080 & 0,0159 & 0,0128 \\
\hline Sentido (S) & & 0,0363 & 0,0299 & $<0,0001$ & $<0,0001$ & $<0,0001$ \\
\hline Interação TxS & & $<0,0001$ & 0,0004 & 0,0500 & 0,7293 & $<0,0001$ \\
\hline C.V. ${ }^{2}(\%)$ & & 11,87 & 29,35 & 26,03 & 25,59 & 26,72 \\
\hline
\end{tabular}

${ }^{1}$ Médias \pm desvio padrão seguidas de teste de Tukey a $5 \%$ de probabilidade; ${ }^{2}$ C.V. $=$ Coeficiente de Variação. Fonte: Autores.

Nota-se que variação na espessura dos couros foi em relação da concentração de tanino vegetal utilizada no curtimento e quanto ao sentido de retirado do corpo de prova. O sentido transversal apresentou maior espessura, variando de 1,03 a $1,14 \mathrm{~mm}$ 
e da longitudinal de 0,87 a 1,12mm. Fujikura et al. (1988) afirmam que a espessura da derme da pele é determinada, principalmente, pela proporção de distribuição das fibras colágenas. Dessa forma, seria uma explicação para o fato da espessura do couro ser variável, nos diferentes sentidos do couro (longitudinal ou transversal ao comprimento do corpo) onde são retirados os corpos de provas.

O tratamento com $10 \%$ de tanino no sentido longitudinal apresentou os maiores valores para a força aplicada no teste e deformação, 155,93 N e 58,40mm, respectivamente (Tabela 4). Todavia, quando analisado a resistência a tração, tanto usando $10 \%\left(15,59 \mathrm{~N} / \mathrm{mm}^{2}\right)$, como $12 \%\left(18,07 \mathrm{~N} / \mathrm{mm}^{2}\right)$ de tanino vegetal no curtimento avaliando o sentido longitudinal do couro, os resultados foram semelhantes e superiores aos obtidos quando utilizado $14 \%$ de tanino na etapa de curtimento, neste mesmo sentido de corte do couro. Tudo indica que a adição de 14\% de tanino apenas no curtimento, tenha reagido com todas as fibras colágenas, necessitando de mais um percentual de tanino na etapa de recurtimento, para complementação do processo de reticulação que deve ocorrer entre as fibras colágenas e o agente curtente. Com a adição de $12 \%$ de tanino no curtimento, deve ter ocorrido uma maior abrangência entre todas as fibras colágenas e depois com a adição de mais $2 \%$ de tanino no recurtimento completou gradativamente esse processo de reticulação, resultando em maior resistência no teste de tração do couro. O teste de tração é muito importante para determinar a qualidade de resistência do couro, podendo ser utilizado 10 ou $12 \%$ de tanino vegetal no curtimento e $4 \%$ ou $2 \%$ de tanino vegetal no recurtimento, respectivamente.

O rasgamento progressivo não houve efeito de interação entre a concentração de tanino utilizado no curtimento com o sentido do couro avaliado, com médias gerais de 1,07 mm para espessura, 74,45 $\mathrm{N}$ para força e 70,64 N/mm para o rasgo (Tabela $5)$.

Tabela 5. Rasgamento progressivo de couros de tilápias do curtidos com diferentes concentrações de taninos analisados nos sentidos longitudinal e transversal.

\begin{tabular}{lcccc}
\hline \multicolumn{1}{c}{ Couros de tilápia do Nilo } & Espessura $(\mathrm{mm})$ & Força $(\mathrm{N})$ & Rasgo $(\mathrm{N} / \mathrm{mm})$ \\
\hline \multirow{2}{*}{$10 \%$ tanino } & Longitudinal & $1,07 \pm 0,01$ & $63,10 \pm 11,35$ & $60,13 \pm 10,51$ \\
& Transversal & $1,07 \pm 0,01$ & $80,00 \pm 5,55$ & $74,81 \pm 4,17$ \\
\multirow{2}{*}{$14 \%$ tanino } & Longitudinal & $1,02 \pm 0,04$ & $67,42 \pm 7,03$ & $66,32 \pm 4,32$ \\
& Transversal & $1,04 \pm 0,03$ & $83,30 \pm 8,85$ & $82,99 \pm 12,35$ \\
& Longitudinal & $1,17 \pm 0,10$ & $69,50 \pm 4,95$ & $59,90 \pm 10,74$ \\
& Transversal & $1,05 \pm 0,02$ & $84,80 \pm 10,35$ & $80,55 \pm 9,91$ \\
\hline Efeitos principais & & & & \\
\hline Tanino & $10 \%$ & $1,07 \pm 0,01$ & $71,55 \pm 2,90$ & $67,47 \pm 3,17$ \\
& $12 \%$ & $1,03 \pm 0,04$ & $75,32 \pm 0,87$ & $73,90 \pm 3,26$ \\
& $14 \%$ & $1,11 \pm 0,05$ & $76,40 \pm 1,95$ & $70,23 \pm 0,41$ \\
\hline Sentido & Longitudinal & $1,08 \pm 0,01$ & $66,72 \pm 7,73^{\text {bl }}$ & $62,38 \pm 8,26^{\mathrm{b}}$ \\
& Transversal & $1,05 \pm 0,02$ & $82,70 \pm 8,25^{\mathrm{a}}$ & $79,45 \pm 8,81^{\mathrm{a}}$ \\
\hline Probabilidades & & & 0,7386 & \\
\hline Tanino (T) & & 0,1841 & 0,6125 \\
Sentido (S) & & 0,4253 & 0,0036 & 0,0023 \\
Interação TxS & & 0,2080 & 0,9174 & 0,7869 \\
\hline C.V. ${ }^{2}$ (\%) & 13,45 & 27,79 & 29,81 \\
\hline
\end{tabular}

${ }^{1}$ Médias \pm desvio padrão seguidas de teste de Tukey a 5\% de probabilidade; ${ }^{2} \mathrm{C} . \mathrm{V} .=$ Coeficiente de Variação. Fonte: Autores. 
Mas, avaliando isoladamente os sentidos de retirada dos corpos de provas, o sentido transversal apresentou diferenças significativas de $5 \%$ de probabilidade para as variáveis força aplicada no teste $(82,70 \mathrm{~N})$ e no rasgo $(79,45 \mathrm{~N} / \mathrm{mm})$, sendo maiores que os apresentados no sentido longitudinal (Tabela 5).

Vieira et al. (2008) avaliaram couros de tilápias curtidas com 10 e $12 \%$ de tanino vegetal e recurtidas com $4 \%$ de tanino vegetal. Os autores relataram que os couros com $12 \%$ de tanino vegetal e $4 \%$ de tanino no recurtimento apresentaram significativamente maior resistência a tração $(13,48 \mathrm{~N} / \mathrm{mm} 2)$, mas, não apresentaram diferença na espessura $(0,69$ e $0,72 \mathrm{~mm})$, alongamento (66,30 e 75,50\%) e rasgamento progressivo (36,66 e 35,69N/mm), quando usado $10 \%$ de tanino e $12 \%$ de tanino no curtimento e $4 \%$ de tanino no recurtimento. Mas, os resultados obtidos para os valores médios (sentido longitudinal e transversal) da tração e do rasgamento progressivo, respectivamente para couros com 10\% (12,40 N/mm2 e 67,47N/mm) e 12\% $(14,09 \mathrm{~N} / \mathrm{mm} 2$ e 73,90N/mm) de tanino vegetal, deste trabalho, foram superiores aos relatados por Vieira et al. (2008), utilizando os mesmos níveis (10\% e 12\%) de tanino vegetal no curtimento. Mas, tal fato se deve ao tamanho da pele (acima de 1000g), consequentemente, maior quantidade de fibras colágenas para reagir com os agentes curtentes e obtenção de um couro mais resistente.

Rocha et al. (2020) observaram diferença significativa para a determinação do rasgamento progressivo $(59,68 \mathrm{~N} / \mathrm{mm}$ e $49,44 \mathrm{~N} / \mathrm{mm})$, força aplicada ( $45 \mathrm{~N}$ e $37,40 \mathrm{~N})$ neste teste, na deformação $(63 \mathrm{~mm}$ e $36,60 \mathrm{~mm})$ e alongamento $(104,60 \%$ e $61 \%)$ quando avaliado o sentido longitudinal e transversal, respectivamente. Estes autores relataram que no sentido longitudinal do couro os valores para todos esses parâmetros mencionados anteriormente foram maiores. Apenas para tração $(15,40 \mathrm{e}$ $15,00 \mathrm{~N} / \mathrm{mm} 2)$ que não houve diferença para o sentido do couro. Mas, os resultados de tração, deformação e alongamento relatados por Rocha et al. (2020) foram superiores aos obtidos neste experimento, enquanto os resultados de rasgo e a força aplicada no rasgamento progressivo foram superiores.

Estes resultados podem estar diretamente relacionados com o tamanho das peles utilizadas para o processo de curtimento, assim como o fato de existir uma maior quantidade de fibras colágenas finas que fazem uma maior amarração no couro, intensificando a sua resistência. Dessa forma analisando quantitativamente as fibras colágenas notou-se que o percentual de fibras finas realmente foi muito superior as fibras espessas presentes nos couros de tilápia do Nilo abatidas com mais de 1001g. Quando analisado a distribuição das fibras colágenas finas e espessas quanto ao sentido do couro, notou-se que no sentido longitudinal dos couros de tilápia apresentou menor percentual em relação a transversal para as fibras finas, enquanto as fibras espessas ocorreram o inverso, ou seja, maior percentual se encontra no sentido longitudinal (Tabela 6).

Tabela 6. Percentuais de fibras de colágenas finas e espessas nos couros de tilápia nos sentidos longitudinal e transversal

\begin{tabular}{lcc}
\hline & \multicolumn{2}{c}{ Fibras colágenas (\%) } \\
\cline { 2 - 3 } & Finas (\%) & Espessas (\%) \\
\hline Longitudinal & $60,70 \pm 2,10$ & $39,30 \pm 2,10$ \\
Transversal & $64,70 \pm 3,07$ & $35,90 \pm 3,07$ \\
\hline Média & $62,40 \pm 2,89$ & $37,60 \pm 2,89$ \\
\hline
\end{tabular}

Fonte: Autores.

Essa distribuição de fibras colágenas está diretamente correlacionada com a resistência dos couros. As fibras finas amarram as fibras espessas, podendo, dessa forma dar melhor estruturação e resistência ao couro após o processo de curtimento. Isto porque as fibras finas proporcionam uma melhor amarração da estrutura histológica desses couros, gerando uma maior resistência à tração, alongamento e rasgamento progressivo. Como o couro de tilápia apresenta uma maior proporção de fibras finas $(62,40 \%)$ para espessa $(37,60 \%)$, isto faz com que estas sejam amarradas mais intensamente, proporcionando maior 
resistência ao couro.

Como no sentido transversal existe uma maior proporção de fibras finas em relação as espessas, isto faz com que o couro seja mais estruturado, amarrado, impedindo que aumente o rasgo à medida que vai aumentando a força. Pode-se observar na Tabela 5 que no sentido transversal $(79,45 \mathrm{~N} / \mathrm{mm})$ do couro a resistência foi maior comparado ao longitudinal (62,38 N/mm), consequentemente exigindo maior força para realização do teste (Tabela 5). No entanto, essa quantidade de fibras finas amarrando as fibras espessas, tende a dificultar mais o deslizamento das fibras em sí, proporcionando uma menor elasticidade ao couro no sentido transversal como pode ser observado na Tabela 4, onde o alongamento foi significativamente menor $(57,19 \%)$ comparado ao sentido longitudinal $(83,63 \%)$ que apresentou maior quantidade de fibras espessas (Tabela 6).

\section{Conclusão}

As Tilápias do Nilo abatidas com maiores pesos, proporcionaram couros mais espessos, com maior resistência a tração e alongamento, bem como o rasgamento progressivo. Portanto, o mais indicado é abater tilápia com peso acima de $1 \mathrm{~kg}$, com a finalidade de aproveitamento das peles para o curtimento com tanino vegetal para a produção de vestuários, bolsas entre outros produtos. Para as peles de peixes acima de $1 \mathrm{~kg}$ deve-se utilizar de $10 \%$ de tanino vegetal na etapa de curtimento e $4 \%$ de tanino na etapa de recurtimento ou $12 \%$ e $2 \%$ de tanino vegetal. Os couros dessa categoria de tamanho apresentam maior resistência a tração no sentido longitudinal.

Recomenda-se novas pesquisas de novos percentuais de tanino sintético e vegetal para o curtimento das peles, assim como a análise de resistência no sentido vertical do couro, sugere-se também que seja avaliado a microscopia eletrônica de varredura.

\section{Agradecimentos}

À Universidade Estadual de Maringá, ao CNPq pelas condições proporcionadas para execução do experimento. Ao abatedouro Peixe Sol Nascente Ltda de Mandaguaçu- PR e ao abatedouro Bom futuro indústria e comércio de peixe de CuiabaMT pelo fornecimento das peles para realização da pesquisa.

\section{Referências}

ABNT. (2014). NBR ISO 3376: couro - Ensaios físicos e mecânicos - determinação da força de rasgamento progressivo. Parte 1: rasgamento de extremidade simples. Associação Brasileira De Normas Técnicas - ABNT. Rio de Janeiro.

ABNT. (2016). NBR 2589: 2016 determinação da espessura. Associação Brasileira De Normas Técnicas - ABNT. Rio de Janeiro: p. 2.

ABNT. (2016). NBR ISO 16511: couro - Ensaios químicos - Preparação de amostras de couro para análise química. Parte 2: rasgamento de extremidade simples. Associação Brasileira De Normas Técnicas - ABNT. Rio de Janeiro.

ABNT. (2020). NBR ISO 11030: couro - Ensaios físicos e mecânicos - determinação de substâncias extraíveis em diclorometano. Parte 5: rasgamento de extremidade simples. Associação Brasileira De Normas Técnicas - ABNT. Rio de Janeiro.

ABNT. (2020). NBR ISSO 11057: couro - Ensaios físicos e mecânicos - determinação do pH e da cifra diferencial. Parte 4: rasgamento de extremidade simples. Associação Brasileira De Normas Técnicas - ABNT. Rio de Janeiro.

ABNT. (2020). NBR ISO 10455: couro - Ensaios físicos e mecânicos- climatização de materiais usados na fabricação de calçados e correlatos. Parte 2: rasgamento de extremidade simples. Associação Brasileira De Normas Técnicas - ABNT. Rio de Janeiro.

Araujo, C., \& Reynol, F. (2017). Produção de tilápia cresce 223\% em de anos. Embrapa.

Boscolo, W.R.; Feiden, A. (2007). Industrialização de Tilápias. Toledo: GFM Gráfica e Editora, 272p.

Boscolo, W. R., Hayashi, C., Soares, C. M., Furuya, W. M., \& Meurer, F. (2001). Desempenho e características de carcaça de machos revertidos de tilápias do Nilo (Oreochromis niloticus), linhagens tailandesa e comum, nas fases inicial e de crescimento. Revista Brasileira de Zootecnia, 30, $1391-1396$.

Franco, M. L. R. S., Franco, N. P., Gasparino, E., Dorado, D. M., Prado, M., \& Vesco, A. P. D. (2013). Comparação das peles de tilápia do Nilo, pacu e tambaqui: Histologia, composição e resistência. Archivos de zootecnia, 62(237), 21-32. 
Franco, MLRS.; Uchimura, CM.; Prado, M.; Yajima, EM.; Gasparino, E.; Silva, SCC (2013). Quality of the skin of salmon, Salmo solaris: resistance test. Arquivos de Ciências do Mar. v.46, n.1, p. 90 - 95.

Fujikura, K.; Kurabuchi, S.; Tabuchi, M.; Inoue, S. (1988). Morphology and distribuition of the skin glands in Xenopus laevis and their response to experimental stimulation. Zoological Science, Tokyo, v. 5 p. 415-430.

Godoy, L. C., Gasparino, E., Franco, M. L. R. S., Franco, N. P., \& Dourado, D. M. (2010). Testes físico-mecânicos e físico-químicos do couro da tilápia vermelha. Arquivo Brasileiro de Medicina Veterinária e Zootecnia, 62, 475-480.

Hilbig, C. C., Fockink, D. H., Maluf, M. L. F., Boscolo, W. R., \& Feiden, A. (2013). Resistência do couro de tilápia e composição centesimal da pele nas operações de ribeira e curtimento. Scientia Agraria Paranaensis, 12(4), 258-266.

Hoinacki, E. \$ Gutheil N.C. (1989). Peles e couros: origens, defeitos e industrialização. 2. ed. Porto Alegre: CEP SENAI de Artes Gráficas, 320 p.

Kubitza, F., \& Campos, J. L. (2006). Aproveitamento dos subprodutos do processamento de pescados. Panorama da aquicultura, 16(94), 23-29.

Larezzi, A.D. (1988). Peles de peixes: matéria-prima para confecções, calçados e acessórios de moda. Setor Couro, v.19, p.8-9.

Neu, D. H., Dallagnol, J. M., Klein, S., Maluf, M. L. F., Franco, M. L. R. S., \& Boscolo, W. R. (2015). Resistência do couro de tilápia do Nilo submetido a diferentes processos de curtimento. Archivos de zootecnia, 64(247), 291-298.

Peixe BR. Associação Brasileira de Piscicultura. Anuário Peixe BR da Piscicultura (2021). São Paulo: Peixe BR, 2 Peixe BR. Associação Brasileira de Piscicultura. Anuário Peixe BR da Piscicultura 2021. São Paulo: Peixe BR.

Pereira, A. S., Shitsuka, D. M., Parreira, F. J., \& Shitsuka, R. (2018). Metodologia da pesquisa científica. [e-book].

Prado, M., Franco, M. L. R. S., Bielawski, K., Souza, E. D., Gasparino, E., Silva, S. C. C., \& Del Vesco, A. P. (2014). Características de Resistência dos Couros de Pseudoplatystoma sp. Submetidos a Alterações nas Etapas do Processo de Curtimento. Rev. Cient. Prod. Anim, 16, 46-59.

SAS Institute Inc., (2010). The data analysis for this paper was generated using SAS/STAT software, Version 9.3 of the SAS System for Windows. Copyright $\odot$ 2010 SAS Institute Inc. SAS and all other SAS Institute Inc. product or service names are registered trademarks or trademarks of SAS Institute Inc., Cary, NC, USA.

SILVA, APD. (2012). Características e Composição da pele de peixe de água doce. Dissertação de Graduação. Curitiba. Universidade Federal do Paraná.

Simões, M. R., Ribeiro, C. D. F. A., Ribeiro, S. D. C. A., Park, K. J., \& Murr, F. E. X. (2007). Composição físico-química, microbiológica e rendimento do filé de tilápia tailandesa (Oreochromis niloticus). Food Science and Technology, 27, 608-613.

Souza, M. L. R., Casaca, J. M., Ferreira, I. C., Ganeco, L. N., Nakagki, L. S., Faria, R. H. S., ... \& Rielh, A. (2002). Histologia da pele e determinação da resistência do couro da tilápia do Nilo e carpa espelho. Revista do Couro, 159, 32-40.

Souza, M. L. R., \& da Silva, L. O. (2005). Efeito de técnicas de recurtimento sobre a resistência do couro da tilápia do Nilo (Oreochromis niloticus L. Acta Scientiarum. Animal Sciences, 27(4), 535-540.

Souza, M. L. R., Cucatti, T., Andrade, M. B., Godoy, L. C., Tozzi, M. A. C., Cavallieri, R. F., ... \& Silva, L. O. (2004). Diferentes técnicas de recurtimento em peles de tilápia-do-Nilo (Oreochromis niloticus): qualidade de resistência. Ensaios Cienc, 8(2), 195-202.

Souza, M. L. R. (2007). Tecnología para procesamiento de pieles de pescados. Maringá: Eduem, Coleção Fundamentum, 35, 61p.

Souza, M. L. R., de Matos Casaca, J., da Silva, L. O., Ganeco, L. N., Nakaghi, L. S. O., Faria, H. S. A., ... \& do Prado Franco, N. (2004). Resistência da pele de carpa espelho (Cyprinus carpio specularis) curtida pelas técnicas ao cromo e bioleather. Acta Scientiarum. Animal Sciences, 26(4), 421-427.

Souza, M. L. R.; Gasparino, E.; Penha, BG.; \& Coradini, MF. (2017). Physicochemical and mechanical characteristics of cobia (rachycentron canadum, linnaeus, 1766) leather submitted to different tanning agents in the retanning step. International Journal of Latest Research in Science and Technology, v. 6, p. 8-13.

Souza, M. L. R., Viegas, E. M. M., Kronka, S. N., Amaral, L. A., Parisi, G., Coradini, M. F., \& Goes, E. S. R. (2020). Cold and hot smoked nile tilapia fillets: quality and yield of pigmented and unpigmented fillets. Italian Journal of Food Science, 32(2).

Souza, MLR.; Valdez, MDCA.; Hoch, ALV.; Oliveira, KF.; Matos, IR.; Camin, AM. (2006). Avaliação da resistência da pele de tilápia do Nilo (Oreochromis niloticus) nos sentidos longitudinal, transversal e diagonal, depois de submetida ao curtimento com sais de cromo e recurtimento com diferentes agentes curtentes. Acta Scientiarum Animal Sciences, Maringá, v.28, n.3, p.361-367.

Souza, M. L. R. D., Casaca, J. D. M., Nakaghi, L. S. O., Franco, N. D. P., Silva, L. O. D., Dourado, D. M., \& Viegas, E. M. M. (2006). Efeito da técnica de curtimento e do método utilizado para remoção da pele da tilápia-do-nilo sobre as características de resistência do couro. Revista Brasileira de Zootecnia, 35, $1273-1280$.

Souza, MLRD.; Casaca, JDM.; Nakaghi, LSO.; Franco, NDP.; Silva, LOD.; Dourado, DM.; \& Viegas, EMM. (2006). Efeito da técnica de curtimento e do método utilizado para remoção da pele da tilápia-do-nilo sobre as características de resistência do couro. Revista Brasileira de Zootecnia, 1273-1280.

Uzeika, R. Estudo histoquímico, ultra-estrutural e morfométrico da pele de duas espécies de peixes siluriformes. 1999. Monografia (Bacharel em Ciências Biológicas) Universidade para o Desenvolvimento do Estado e da Região do Pantanal, Campo Grande.

Vieira, A. M., Kachba, Y. R., Franco, M. L. R. S., Oliveira, K. F., Godoy, L. C. \& Gasparino, E. (2008). Curtimento de peles de peixe com taninos vegetal e sintético. Acta Scientiarum - Animal Sciences, 30(3), 359-63

Yoshida, G. M., Kunita, N. M., Souza, M. L. R., \& Gasparino, E. (2016). Análises mecânicas e físico-químicas de couros de tilápia, cachara e salmão. Archivos de zootecnia, 65(251), 349-355. 